\title{
An Overview of the Status and Conservation Initiatives of Red Panda Ailurus fulgens (Cuvier, 1825) in Nepal
}

\author{
Damber Bista $^{1}$ and Rajiv Paudel ${ }^{2}$ \\ Corresponding author: Damber Bista \\ Email: damber.bista@redpandanetwork.org
}

\begin{abstract}
The existing status of Red Panda Ailurus fulgens in Nepal is poorly known. Current work attempts to put the information on Red Panda status together from Nepal and the conservation initiatives taken so far in the country. Red Panda inhabits eastern Himalayan temperate broadleaved forest with bamboo in the understory with an altitudinal range preference of 2400-3900 m. The Red Panda population in Nepal is about 314 individuals. Although the majority of potential habitat i.e. $62 \%$ lies in community managed and national forest, a very few initiatives have been started for the research and conservation of this species outside the protected areas. The Red Panda is protected in Nepal. Forest fire, rotational grazing, slash and burn cultivation, timber and fire wood collection, predation by dogs, natural dying of ringal bamboo species, drought, landslide and lack of awareness are identified as the major conservation threats for Red Panda throughout its habitat within the country.
\end{abstract}

Key Words: Community managed forest, Conservation policy, Protected Areas, Red Panda, Threats

\section{Introduction}

The Red Panda is distributed from Nepal in the West through China, India, Bhutan and Myanmar (Ghose \& Dutta, 2011). Its westernmost occurrence in Nepal is recorded so far in Mugu District $\left(82^{\circ} \mathrm{E}\right.$, Sharma, 2008), Western Nepal and eastern most in the Minshan mountains and upper Min Valley of Sichuwan Province, South-Central China $\left(104^{\circ} \mathrm{E}\right)$ with a narrow extent of north-south distribution from $25^{\circ} \mathrm{N}$ to $33^{\circ} \mathrm{N}$ (Ellerman \& Morrison-Scott 1966, Macdonald 1984, Corbet \& Hill 1992, Chaudhary 1997). In Nepal, only the nominate sub-species Ailurus fulgens fulgens occurs.

Red Panda Network, P. O. Box 2785, Baluwatar, Kathmandu, Nepal

Red Panda Network, P. O. Box 2785, Baluwatar, Kathmandu, Nepal, rajiv.paudel@redpandanetwork.org 
Red Panda inhabits eastern Himalayan temperate broadleaved forest with bamboo in the understory with an altitudinal range preference of 2400-3900 m (Pradhan et al., 2001; Yonzon and Hunter, 1991). The estimated global population size of the Red Panda on the basis of average density of one Panda $/ 4.4 \mathrm{~km}^{2}$ is $16,000-20,000$ within the total potential Red Panda habitat of 142,000 $\mathrm{km}^{2}$ in five Red Panda range countries (Choudhury, 2001). Recently, IUCN (2011) has estimated the global population of Red Panda to be around 10,000. The Red Panda population in

Nepal is about 314 individuals on the basis of habitat suitability index of $2.9 \mathrm{~km}^{2}$ ecological density within $912 \mathrm{~km}^{2}$ potential habitat (Yonzon et al., 1997).

In Nepal, the Red Panda is a protected species but their numbers are dwindling as intense human pressure affects their habitat. Red Pandas may be near extinction in Nepal with sparse populations found in Langtang and Lambagar - Central Nepal (Yonzon et al., 1991). Despite being such an important species, information on this animal from Nepal is scanty. In the case of Red Panda, the most pressing problem in its conservation is insufficient information regarding its occurrence (Yonzon et al., 1997).

Current work attempts to put information on Red Panda status together from Nepal and the conservation initiatives taken so far herein. It is based on the review of available literature on Red Panda research, monitoring, legislation and conservation to date along with the reflection of the authors' experience.

\section{Abundance and Distribution}

In the global scenario, Nepal is home to approximately $1.9 \%$ of the total global population of the Red Panda estimated on the basis of habitat suitability index. The potential habitat inside the PAs covers about 38 percent of the total potential Red Panda habitat whereas remaining 62 percent of potential habitat lies in community managed and national forest in the country where their population and conservation status is not known in most of the areas (DNPWC/MoFSC/GoN, 2010).

Population and Habitat Viability Assessment (PHVA) Workshop on Red Panda Ailurus fulgens in Nepal had recognized 11 sub populations of Red Panda with an estimation of total population to be around 317 individuals within the confirmed habitat of $592.39 \mathrm{~km}^{2}$ along with the estimation of possible population of 582 individuals within $3244.52 \mathrm{~km}^{2}$ including another potential habitat of $2652.13 \mathrm{~km}^{2}$ (Table. 1). The occupancy of the species was also confirmed in 24 districts with potential habitats in another 12 districts (PHVA, 2010). Recently, the presence had also been recorded from the Kalikot district (Nabin Shahi, pers. comm., 2012), Khotang district (www.ekantipur.com, 2012) and Jajarkot district (www.myrepublica.com, 2012) out of those 12 districts (Figure 1). However, it is yet to be confirmed by scientific research. 
Table 1: Population estimation of Red Panda in Nepal

\begin{tabular}{|l|l|l|l|l|l|}
\hline \multirow{2}{*}{ S.N. } & \multirow{2}{*}{ Sub populations } & \multicolumn{2}{c|}{ Area $\left(\mathbf{k m}^{2}\right)$} & \multicolumn{2}{c|}{ Population } \\
\cline { 3 - 6 } & & Confirmed & Possible & Confirmed & Possible \\
\hline 1 & Annapurnna-Manaslu & 4.18 & 84.23 & 2 & 20.15 \\
\hline 2 & Darchula & & - & & \\
\hline 3 & Dhorpatan & 89.05 & 434.92 & 43 & 104.05 \\
\hline 4 & Gaurishankar & 45.17 & 114.15 & 22 & 27.31 \\
\hline 5 & Kanchanjungha & 111.91 & 160.76 & 67 & 48.13 \\
\hline 6 & Khaptad & 3.57 & 211.22 & 1 & 36.42 \\
\hline 7 & Langtang & 47.83 & 125.7 & 23 & 30.07 \\
\hline 8 & Rara & 55.63 & 1099.16 & 19 & 189.51 \\
\hline 9 & Sagarmatha & 73.71 & 150.96 & 44 & 45.2 \\
\hline 10 & Sakhuwasabha East & 101.88 & 119.01 & 61 & 35.63 \\
\hline 11 & Sakhuwasabha West & 59.46 & 152.02 & 36 & 45.51 \\
\hline & Total & 592.39 & 2652.13 & 317 & 581.98 \\
\hline
\end{tabular}

Source: PHVA, 2010

Based on anecdotal evidence, study reports, sightings and signs, the presence of Red Panda has been confirmed in eight Protected Areas (PAs) of Nepal: Kanchanjungha Conservation Area (RPN, 2010; Mahato and Karki, 2005; Mahato, 2003 and Yonzon, 1996); Sagarmatha National Park (Mahato, 2004); Makalu Barun National Park (Jackson, 1990); Langtang National Park (Thapa, 2009; Karki, 2006; Karki and Zendrzejenski, 2000; Fox et al., 1996; Yonzon et al., 1991; Yonzon and Hunter, 1991; Yonzon, 1989 and Shrestha, 1988); Rara National Park (Sharma, 2008); Manaslu Conservation (Chaudhary, 1992 cited in Yonzon, 1997); Dhorpatan Hunting Reserve (Sharma and Belant, 2009; Subedi, 2009 and Sharma and Kandel, 2007) and Annapurna Conservation Area (Shrestha and Ale, 2001). Recently, its presence had also been recorded from Api Nampa Conservation Area, the westernmost part of Nepal (DNPWC, 2011), although, Mugu District was recorded as the westernmost region in Nepal (Sharma, 2008).

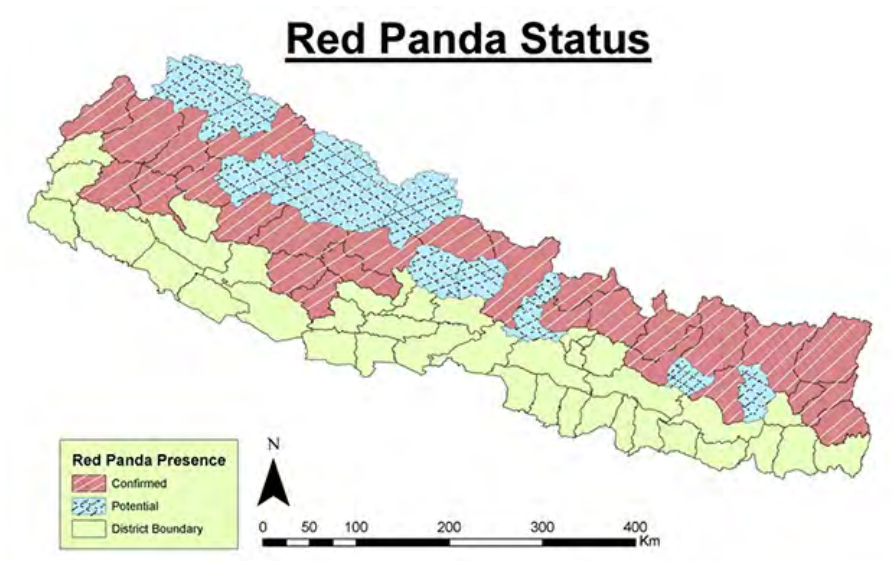

Figure 1: Red Panda distribution districts in Nepal 
harma and Belant (2009) reported the presence of Red Panda within 3000m to 3600m amsl in Dhorpatan Hunting Reserve (DHR) and sighted four Red Pandas. Subedi and Thapa (2011) has revealed the presence of four small isolated groups of Red Panda in which 3 groups bearing cubs inside the DHR. They also analysed the microhabitat and showed the higher abundance of Red Pandas in Tsuga dumosa, Rhododendron, Betula and Arundinaria sp. dominated habitat in altitude between $3200 \mathrm{~m}$ to $3400 \mathrm{~m}$ in Dhorpatan Hunting Reserve. Similarly, there are more than 11 Red Pandas in Rara National Park within an area of 31 $\mathrm{km}^{2}$ (Sharma, 2008).

Langtang National Park (LNP) provides a very suitable habitat for the Red Panda where 73 individuals comprising of four different populations were recorded to be estimated within the suitable habitat of $153.5 \mathrm{~km}^{2}$ (Yonzon, 1989). Later on Yonzon et al. (1991) estimated the existence of 24 individuals of Red Pandas in Langtang National Park which is so low that their survival is questionable within an suitable habitat of $68 \mathrm{~km}^{2}$ available there. Very small populations, 20-50 Red Pandas, have a high probability of extinction even without additional human caused threats. The majority of current subpopulations fall in this range. Even larger populations will become extinct if human threats, such has hunting, predation by domestic dogs, habitat loss, fire, etc. are not urgently addressed (Walker \& Molur, 2010). In LNP, the Red Panda core habitat $60 \%\left(45 \mathrm{~km}^{2}\right)$ is under at high risk due to human pressure primarily because of grazing and firewood collection (Yonzon et al., 1991).

The Panchthar-Ilam-Taplejung (PIT) Corridor has been considered as an important habitat for the Red Panda because it contains $178 \mathrm{~km}^{2}$ or 20\% of total potential Red Panda habitat, which support approximately 25\% of Nepal's Red Panda population, with an estimated 100 individuals (Williams, 2006; Williams, 2004 and Yonzon, 2001). The given population (exactly 106) within the corridor is based on the crude density of one Red Panda/1.67 km² for Singhalila National Park (Pradhan et al., 1989). The population may ranges between 61 individuals, estimated on the basis of ecological density of one Red Panda/2.9 km for Nepal given by Yonzon et al. (1997) and 129 estimated on the basis of ecological density of one Red Panda/1.38 km² for Illam district given by Williams (2004). RPN-Nepal (2010) has recorded Red Panda signs between elevations 2530 and 3790 meters with the highest encounter frequency between 2700 and 3220 meters in Sacred Himalayan Landscape (SHL) and also revealed the higher Red Panda abundance in the east compared to the western part of the area. Ghimire and Bhatta (2010) reported that a Choyatar Community Forest within Jamuna VDC in Ilam District of eastern Nepal is home to 15 Red Pandas. William (2004) has reported some 4 individuals from the community managed and national forest of Jamuna and

Mabu VDCs of Ilam district in eastern Nepal and also revealed the higher abundance of Red Panda in the $2600 \mathrm{~m}-3000 \mathrm{~m}$ range. The area of Choyatar Community Forest is only $1.5 \mathrm{~km}^{2}$ (DFO, 2012). Therefore, that forest can't harbor much population even if the crude density (minimum) of one Red Panda $/ 1.38 \mathrm{~km}^{2}$ for Illam district is considered (William, 2004). Mahato et al. (2011) observed the highest encounter rate at $3200 \mathrm{~m}$ in the same area, which is close to the recorded mean altitude of Red Panda occurrence in the adjoining Singhalila National Park in Darjeeling, West Bengal, India (Pradhan et al., 2001). Williams 
et al. (2011) has also estimated 28 individuals of Red Panda from three VDCs namely Kalikhola, Surumkhim and Yamphudin VDCs of Taplejung district. Out of which first two falls outside the PAs.

\section{Conservation policy and initiatives}

Conservation of rare species like Red Panda has been emphasized in various conservation related documents of Nepal. National Conservation Strategy (1988) has also clearly pointed out the need of preserving rare or endangered species and their habitats. Master Plan for Forestry Sector (1988) has made the provision of protection of representative examples of ecosystems unique to Nepal, areas of Special scientific, scenic, and recreational or cultural values and maintenance of the ecological and environmental balance for the sustained wellbeing of the nation. Plan for the Conservation of Ecosystems and Genetic Resources (1988) has formulated the relevant policies on In-situ and ex-situ conservation of biodiversity. Nepal Environmental Policy and Action Plan (1993) has emphasized for the preservation of endemic and endangered species and their habitats and the promotion of private and public institutions for biological resources inventory and conservation. Nepal Biodiversity Strategy (2002) urges extensive research and maintenance of the endangered and indicator species including Red Panda and their habitat. The strategy has recognized and formulated a mixture of strategies to safeguard the rich and varied biological diversity as well as for the development and implementation of species conservation action plan for keystone species like Red Panda which emphasizes population surveys, monitoring, protecting key habitats, and relocation and restoration of such species. Constitution of Nepal (2007) has also made the provision of maintenance of $40 \%$ of forest in the country along with the protection of associated rare wildlife species.

The Red Panda is designated as vulnerable species (IUCN, 2011), protected in Nepal by National Park and Wildlife Conservation Act, 1973 which prohibits its killing or capture dead or alive and an appendix I species under the Convention on International Trade in Endangered Species of Wild Fauna and Flora (CITES). The NPWC Act, 1973, has made the clear provision of complete protection of protected wildlife of Nepal including Red Panda under the Section 10 of the Act. In Section 26 (2) of the Act there is a provision of fine upto 40,000-75,000 to any person who kills or tries to kill Red Panda or jailed for 1-10 years, or both.

An effort of the conservation of Red Panda through the establishment of conservation area inside the LNP has been so far initiated after the declaration of Red Panda Conservation Area by DNPWC in 1990 as per the recommendation in Langtang National park Management Plan, 1977. DNPWC/GoN has formulated a Red Panda conservation action plan for LNP and buffer zone, Nepal (2009-2013) for the systematic conservation of the species within the demarcated area which is presently under implementation. DNPWC/GoN is formulating Red Panda conservation action plan (pers. comm. Prof. Shah, K.B., 2012). Its promulgation is expected to be the mile stone towards the conservation initiation of this flagship species. 
Some initiations have also been started outside the protected areas for the sake of conservation of this species and Red Panda Network, (RPN) is leading this effort since 2007 in Nepal. Since then RPN has been working in PIT-Corridor of Eastern Himalayan region of Nepal in the field of Red Panda research and community based monitoring through mobilizing CFUGs. A curriculum on Red Panda conservation for the school level has been so far developed by RPN which is about to be implemented as local curriculum in Taplejung district. RPN has targeted to identify and monitor $533 \mathrm{~km}^{2}$ or $40 \%$ of the potential Red Panda habitat in Nepal by the end of the year 2015. Besides, Red Panda Network-Nepal (RPN-Nepal) is also active with the same objective in the country.

\section{Conservation issues}

Yonzon \& Hunter (1991) identified the presence of Chouri (Yak), their herders and dogs as major detrimental factors to Red Pandas in LNP. They also revealed that 57 percent of total mortality were human related. Yonzon et al. (1991) indicated towards the firewood collection and cattle grazing as pressure inducing factor for Red Panda survival in the area. The authors have also recorded seven death tolls of Red Panda in PIT-corridor within six months from October 2011 to March 2012. Out of seven, four individuals were recorded to be killed due to the attack by dogs, one by the predation due to Martes flavigula, one was speculated to be due to the poaching intention by human and another one was supposed to be due to the natural death due to the infection in mammary gland. Yonzon (1989) recorded the cub's mortality rate of Red Panda to be $83-86 \%$ and $67 \%$ in 1986 and 1987 . The proximate causes of such high mortality were associated with the disturbances from human related activities. Williams (2006) has revealed that the creation of road through Jamuna and Mabu VDCs in Ilam District may threaten Red Panda and its habitat. Choudhury (2001) had also revealed road construction as a culprit for habitat loss and fragmentation. The major threats to the Red Panda identified throughout SHL were loss of forest and ringal bamboo as a result of collection of timber, fire wood, ringal bamboo and other non-wood forest products and bamboo flowering (RPN-Nepal, 2010). In a report submitted to Ocean Park Conservation Foundation - Hong Kong, RPN (2010) has identified forest fire; rotational grazing; slash and burn cultivation; timber and fire wood collection; predation by dogs, eagle, yellow throated marten, leopard; natural dying of ringal bamboo species; drought; landslide and lack of awareness as major threats for the Red Panda in Eastern Nepal. (DNPWC/MoFSC/ GoN, 2010) has also indicated towards the similar threats existing in LNP. In addition, it has also indicated towards the weak incentives for conservation initiatives and accidental trapping and killing. Choudhary (2001), also agreed with the opportunistic and accidental caught of Red Panda in snares during hinting wild pig, deer, serow, goral etc. However, hunting does not appear to be as a serious threat for Red Panda. Recently, six Red Pandas were recorded to be killed in Nayakwada and Rokayagaon VDCs of Jajarkot in the past five months. Out of six, two of them were trapped in net and killed by the locals while poachers killed other three Pandas. Similarly, children grazing cattle in the jungle killed another Panda using catapult (www.myrepublica.com, 2012).

The legal trade of Red Panda stopped following the listing of Red Panda on CITES Appendix I (TRAFFIC, 1991). However, illegal trapping and trade are occasionally 
reported. Recently, in 2005, Red Panda furs from a Nepalese tradesman in the Gola pass in the Kanchanjungha Conservation Area, was confiscated (Glatston and Geabauer, 2011). Other incidents that have come to the attention of the authors in 2010, is the confiscation of Red Panda tail from a local hotel owner along the way to Pathibhara shrine in Taplejung district. Recently, two persons were confiscated with a pelt of Red Panda in Kathmandu (www.thehimalayantimes, 2012). Oppitz (1980) had reported that shamans of the Northern Magar tribe in the Dhaulagiri Region of Western Nepal and Kami people thereof use the skin and fur of Red Panda in their ritual dress because they consider the Red Panda to be a protective animal which guards the wearer against the attacks of aggressive spirits. However, the belief is not found to be practiced presently.

\section{Conclusion}

Red Panda is an indicator species of areas with mature Eastern Himalayan Broadleaf Forest. Although legal trade and poaching of Red Panda is found to be stopped in Nepal there are still existing a number of threats like forest fire, grazing, timber and fire wood collection, predation, natural dying of ringal bamboo species, drought, landslide and lack of awareness as vital issues. The legal provisions made for the conservation of Red Panda seems to be sufficient, however, there is yet to bring change in the scenario by implementing the provisions. To avoid extinction of Red Pandas in Nepal in the short to mid-term future, it is vital to fully restore habitats between subpopulations and immediately address human caused threats. The available information is not sufficient, therefore, an intensive research on population dynamics, status and distribution, home range size and resource requirements of wild Red Panda should be immediately initiated to disclose the exact information of this animal from the country. Furthermore, it is also necessary to change the people's attitude by new initiatives for awareness building and conservation friendly alternatives for the enhancement of their livelihood with high valued incentives via eco-tourism and sustainably living practices.

\section{References}

Catton, C. 1990. Pandas, Christopher Helm Ltd., Bromley, Kent, UK.

Choudhary, A.U. 2001. An Overview of the Status and Conservation of the Red Panda Ailurus fulgens in India, with Reference to its Global Status, Oryx: 35:250-259.

Choudhaury, A.U. 1977. Red Panda Ailurus fulgens (F. Cuvier, 1825) in the North-East with an Important Record from the Garo Hills. Journal of Bombay Natural History Society 94: 145-147.

Corbet, G.B. and Hill, J.E. 1992. The Mammals of the Indo-malayan Region: A Systematic Review. Oxford University Press, Oxford.

Cuvier, F. 1825. Histoire naturelle Des Mamniferes avec.des Figures Originales.calories, Desinees d’ Apris des Animaux Vicants, 2, pp.1-3. Peris. 
DNPWC/GoN. 2011. Api-Nampa Conservation Area. Department of National Park and Wildlife Conservation, Babarmahal, Kathmandu, Nepal.

DNPWC/MoFSC/GoN. 2010. Red Panda (Ailurus fulgens) Conservation Action Plan forLangtang National Park, Nepal. Government of Nepal, Ministry of Forests and Soil Conservation, Department of National Parks and Wildlife Conservation, Langtang National Park.

Dorji, S., Varnes, K. and Rajaratnam, R. 2011. Habitat Correlates of the Red Panda in theTemperate Forests of Bhutan, Retrived from http://www.ncbi.nlm.nih.gov/pmc/ articles/PMC3198399/.

Ellerman, J.R. and Morrison-Scott, T.C.S. 1966. Checklist of Palaearctic and Indian Mammals, 1758-1946, 2nd edn. British Museum (Natural History), London.

Fox, J., Yonzon, P. and Podger, N. 1996. Mapping Conflicts between Biodiversity and Human needs in Langtang National Park, Nepal. Conservation Biology. 10(2): 562569.

Ghimire, N. and Bhatta, S. D. (eds.). 2010. Red Pandas from Choyatar, Headlines Himalaya No. 138, December 08-14-2010.

Ghose, D. and Dutta, P.K. 2011. Status and Distribution of Red Panda Ailurus fulgens fulgens in India, Red Panda Biology and Conservation of the First Panda (Ed.) A.R. Glatston, pp. 393-408, Elsevier Inc.

Glatston, A.R. and Gebauer,A. 2011. People and Red Pandas: The Red Panda's Role in Economy and Culture. Red Panda Biology and Conservation of the First Panda (Ed.) A.R. Glatston, pp. 11-25, Elsevier Inc.

GoN. 1973. National Park and Wildlife Conservation Act, 1973. Government of Nepal.

GoN/MFSC. 1988. Master Plan for the Forestry Sector Nepal: Forestry Sector Policy Kathmandu: GoN (Ministry of Forest and Soil Conservation).

GoN/MFSC. 1988. National Conservation Strategy, Government of Nepal/Ministry of Forest and Soil Conservation, GEF and UNDP.117p.

GoN/MFSC. 2002. Nepal Biodiversity Strategy. Kathmandu: Government of Nepal/ Ministry of Forest and Soil Conservation).

IUCN. 2011. IUCN Red List of Threatened Species. Version 2011.2. <www.iucnredlist. org>. Downloaded on 03 April 2012.

Jackson, R. 1990. Threatened wildlife, crop damage and wildlife depredation and grazing in the Makalu-Barun National Park and Conservation Area. The Makalu Barun Conservation Project working Paper publication series. Department of National park and Wildlife Conservation, Kathmandu, Nepal and Woodlands Mountain Institute, West Virginia, USA. 
Karki, J.B. and Jendrzejewski, J. 2000. Biodiversity Conservation in Langtang National Park, Department of National park and wildlife conservation, Kathmandu, Nepal and U.S. peace Crops, Lazimpat, Kathmandu, Nepal.

Karki, J.B. 1999. Report on study of Red Panda habitat at Cholangpati Area of LangtangNational Park. Department of National Park and Wildlife Conservation, Kathmandu, Nepal.

Macdonald, D. (ed.) 1984. The Encyclopaedia of Mammals. 2 Volumes. George Allen \& Unwin, London \& Sidney.

Mahato, N.K.2003. Status of Red Panda Ailurus fulgens (Cuvier, 1825) in the Kanchanjungha Conservation Area. B.Sc. project paper submitted to Institute of Forestry, Tribhuvan University, Pokhara.

Mahato, N.K. 2004. Baseline Survey of Red Panda Ailurus fulgens Status in the Buffer Zone of Sagarmatha National Park. A report submitted to WWF Nepal programme, Kathmandu, Nepal.

Mahato, N.K. and Karki, J.B. 2005. Distribution and Habitat Assessment of Red Panda (Ailurus fulgens) in Kanchanjungha Conservation Area with reference to Riya Samba and Lama Khanak forest. The Nepal Journal of Forestry, Vol. XII, No. 3, 2005.

Oppitz, M. 1980. Schamanen im Blinden Land. Film, 2nd edition on DVD from 2008, Volkerkundemuseum der University, Zurich, Swithzerland, 1980.

PHVA. 2010. Report from wild population group. Population Health and Viability Assessment of Red Panda in Nepal, (Unpublished).

Pradhan, S., Saha,G.K. and. Khan, J.A. 2001. Ecology of the Red Panda Ailurus fulgens in the Singhalila National Park, Darjeeling, India. Biological Conservation 98: 11-18.

RPN. 2010. Baseline Survey of Red Panda Distribution, Abundance, and Population Status in the Eastern Himalaya of Nepal, a report submitted to Ocean Park Conservation Foundation- Hong Kong (Unpublished).

RPN-Nepal. 2010. Study on Ecology, Behavior and Conservation of Red Panda in the Sacred Himalayan Landscape of Nepal, WWF-Nepal.

Sharma, H.P. 2008. Distribution and Conservation Status of Red Panda (Ailurus fulgens) in Rara National Park, Nepal. Final Report. PTES, London.

Sharma, H.P. and R.N. Kandel. 2007. Red Panda Ailurus fulgens in the Dhorpatan Hunting Reserve of Nepal: An Assessment of Their Conservation Status. A Report to People's Trust for Endangered Species, UK. 
Shrestha, M.K. 1988. Vegetation study of Red Panda habitat in Langtang National Park, Central Nepal. Unpubl. M.S. Thesis, Tribhuvan University, Kathmandu.

Shrestha, R. and Ale, S.B. 2001. Species diversity of Modikhola Watershed. King Mahendra Trust for Nature Cosnervation, Annapurna Conservation Area Project, Pokhara, Nepal. 47 pp.

Subedi, T.R. and Thapa, A. 2011. Habitat Status and Distribution of Red Panda (Ailurus fulgens) in Dhorpatan Hunting Reserve, Nepal. Dahal, S. and S. Thapa (Eds.) 2011. Proceedings of Second Seminar on Small Mammals Issues. Small Mammals Conservation and Research Foundation, New Baneshwor, Kathmandu, Nepal, pp.1724.

TRAFFIC (IUCN/WWF). 1991. The smuggling of Endangered Wildlife across the Taiwan Strait. TRAFFIC International, Cambridge, UK.

William, B. H. 2004. The status of Red Panda in Jamuna and Mabu village of Eastern Nepal. Unpublished thesis M.Sc. The faculty of the Department of Environmental Studies. San Jose State University.

Williams, B. H. 2006. Red Panda in Eastern Nepal: How does it fit into Eco-regional Conservation of the Eastern Himalaya? In: J. T. McCarthy (Eds.), Conservation Biology in Asia, Society of Conservation Biology and Resources Himalaya, Kathmandu, Nepal, pp. 236-251.

Williams, et al. 2011. Project Punde Kundo: Community-based monitoring of a Red Panda population in Eastern Nepal, Red Panda Biology and Conservation of The First Panda (Ed.) A.R. Glatston, pp. 393-408, Elsevier Inc.

Yonzon, P. and Hunter,M .L. 1991a. Conservation of the Red Panda (Ailurus fulgens), Biol. Conservat. 57(1991) 1-11.

Yonzon, P. B. 1996. Status of Wildlife in the Kanchanjungha Region: A Reconnaissance Study Report. Report Series no. 23, WWF Nepal Program, pp18.

Yonzon, P. B. and Hunter,M. L. 1991b. Cheese, Tourist and Red Panda in the Nepal Himalayas, Conservation Biology 5 (2):196-202.

Yonzon, P. B. 1989. Ecology and Conservation of Red Panda in the Nepal Himalayas. Ph. D. Dissertation (Unpublished.). University of Marine. USA.

Yonzon, P. B., Jones., R. and Fox, J. 1991. Geographic Information Systems for Assessing Habitat and Estimating Population of Red Pandas in Langtang National Park, Nepal. Ambio 20(7) 285-288..0, 
Yonzon, P., Choudhaury, C. and Vaidya, B. 1977. Status of the Red Panda in the Himalayan Resources Nepal, Kathmandu. pp 21.

http://www.ekantipur.com/2012/07/08/national/red-pandas-sighted

http://e.myrepublica.com/component/flippingbook/book/941-republica-11-july-2012/1republica.html

http://www.thehimalayantimes.com/fullNews.php?headline=Two+held+with+panda+hide \&NewsID=339439 